\title{
Electrostatic effects on the photoreactions of nitrophenyl ethers with nucleophiles
}

\author{
Jordi Marquet* and Chiara Tomasi \\ Departament de Química, Universitat Autònoma de Barcelona, 08193 Bellaterra, \\ Barcelona, Spain \\ E-mail : jordi.marquet@uab.es
}

Dedicated to Professor Roberto A. Rossi on his $60^{\text {th }}$ birthday

(received 21 Aug 03; accepted 30 Sep 03; published on the web 04 Oct 03)

\begin{abstract}
Nucleophilic aromatic photosubstitutions of 1,2-dialkoxy-4-nitrobenzenes by oxygen nucleophiles such as water or alcohols in basic media and in air equilibrated solutions, lead to low yields of substitution, following the "polar" $\mathrm{S}_{\mathrm{N}} \mathrm{Ar}^{*}$ mechanism. Photoreduction of the nitro group is the exclusive process in an inert atmosphere. By using Topologically Controlled Coulombic Interactions (TCCI), the photosubstitution process becomes predominant, allowing the SET mechanism for $\mathrm{S}_{\mathrm{N}} \mathrm{Ar}^{*}$ reactions to occur. This is due, on one hand, to the reduced tendency of the radical anion to be oxidized, and on the other hand, to the removal of electronic density from the nitro group in the radial anion which lowers the rate of proton transfer from the nucleophile radical cation.
\end{abstract}

Keywords: Photosubstitution, electron transfer, nitroaromatics, topologically controlled coulombic interactions (TCCI)

\section{Introduction}

The “Topologically Controlled Coulombic Interactions (TCCI) Effect” has been introduced and used by us to achieve some previously unknown processes in some cases (i.e reductive cleavage of nitrophenyl alkyl ethers), ${ }^{1-3}$ and to alter the normal reductive reactivity in others (i.e regioselectivity change in the reductive cleavage of alkyl phenyl ethers). ${ }^{4,5}$ This effect involves the altering of the normal behavior of a negatively charged intermediate by specifically placing a positive charge in its structure [i.e. through the use of $\omega$-( $N$-methylpiperidinium)-alkyl chains].

Nucleophilic aromatic photosubstitutions in substituted nitroaromatic compounds have been the object of intense research since their discovery in $1956 .{ }^{6}$ A mechanistic borderline between polar $\mathrm{S}_{\mathrm{N}} \mathrm{Ar}^{*}{ }^{7}$ and $\mathrm{S}_{\mathrm{N}} \mathrm{Ar}^{*}$-SET (reactions that take place through single electron transfer from the nucleophile to the excited nitroaromatic substrate) has been established. ${ }^{8-12}$ Another interesting borderline exists between the $\mathrm{S}_{\mathrm{N}} \mathrm{Ar}^{*}$-SET process and the electron transfer initiated 
photoreduction of the nitro group. ${ }^{13,14}$ This mechanism of photoreduction is especially efficient for electron-donor substituted nitroaromatics since in these cases the low energy excited states are of the $\pi-\pi^{*}$ type. ${ }^{15}$ These types of excited states tend to form hydrogen bonds in the nitro group side, ${ }^{16-18}$ and the corresponding radical anions are rather basic (the $\mathrm{pK}_{\mathrm{a}}$ value in water for the protonated radical anion of p-nitrophenol is 3.6, significantly higher than other nitroaromatics, for instance the value for protonated $p$-dinitrobenzene is 1.6). ${ }^{19}$ Generally all these process coexist, making the outcome of the photoreactions complex, and reducing their synthetic usefulness. In Scheme 1 a simplified version of all these mechanisms is depicted.

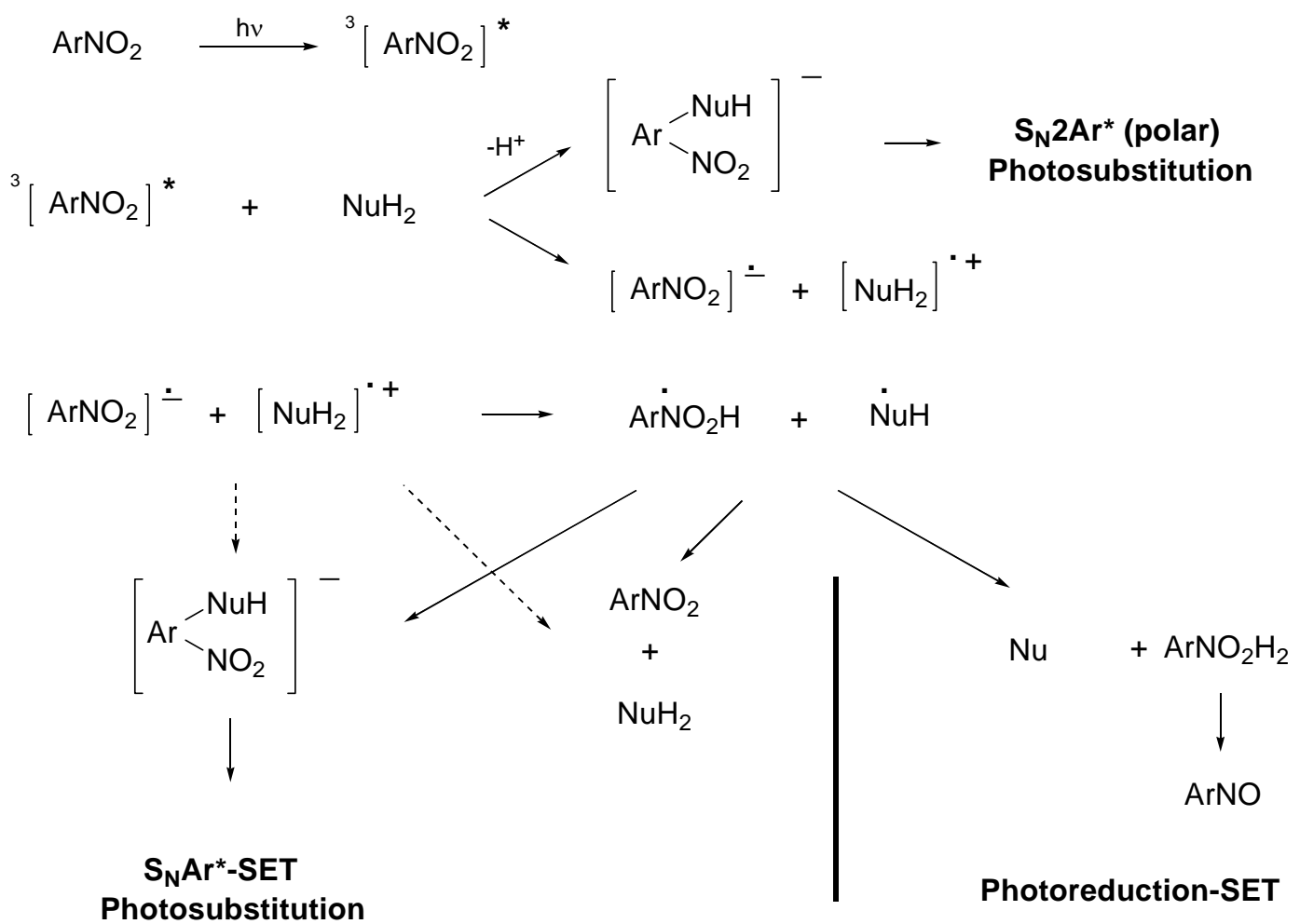

\section{Scheme 1}

As described in Scheme 1 , the $\mathrm{S}_{\mathrm{N}} \mathrm{Ar}{ }^{*}$-SET mechanism, and the SET initiated photoreductions include nitroaromatic radical anions in their mechanistic pathways, and this last process includes also a proton transfer from the nucleophile radical cation to the nitro group in the nitroaromatic radical anion. ${ }^{8}$ Therefore, the photoreactions of TCCI modified nitrophenyl ethers in the presence of nucleophiles (reducing agents) can constitute good examples to test the possibilities of TCCI effects in controlling a complex photoreactivity. In this paper we describe how, by using TCCI effects, the chemoselectivity of the photoreaction can be completely reversed, from total photoreduction to SNAr*-SET photosubstitution.

\section{Results and Discussion}


The substrates to be studied are depicted in Chart 1 . The electroreductive behavior of these compounds has been previously reported by us. ${ }^{2,20}$ Cyclic voltamograms show in all the cases a reversible first wave that indicates the radical anion is stable in the time scale of cyclic voltammetry. A small shift of the standard potential $\mathrm{E}^{0}$ of the couple substrate/radical anion or substrate/zwiterionic radical is observed when comparing 4-nitroveratrole (1) (-1.13 V vs. SCE) and the tetrafluoroborate of N-methyl-N-(2-(2-methoxy-4-nitrophenoxy)ethyl)piperidinium (3) ($1.08 \mathrm{~V}$ vs. SCE).

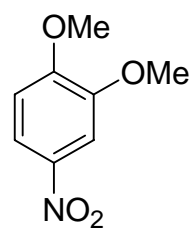

(1)

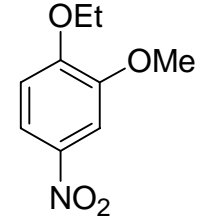

(2)

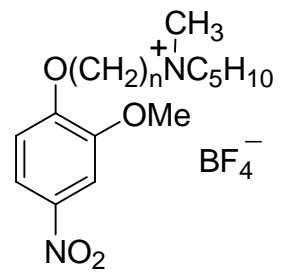

$\mathrm{n}=2$

$\mathrm{n}=5$
(3)

(4)

Chart 1. Irradiation substrates.

Irradiation of a solution of 3-methoxy-4-ethoxynitrobenzene 2 and $0.1 \mathrm{M} \mathrm{NaOH}$ in $\mathrm{MeOH} / \mathrm{H}_{2} \mathrm{O}(1: 1 \mathrm{v} / \mathrm{v})$ in inert atmosphere (argon) for 15 minutes with a 400W lamp through pyrex, led to a complex and tarry mixture with complete disappearance of the starting material. On the other hand, the same procedure carried out in an air equilibrated solution leads to 2ethoxy-5-nitrophenol 5 (20\% preparative yield), 4-nitroveratrole 1 (8\% yield) and traces of 2methoxy-5-nitrophenol 6, together with $67 \%$ of recovered starting material (33\% conversion). The different outcome of these two photoreactions (Scheme 2) can be attributed to oxidation of the radical anion, intermediate in the photoreduction path (this pathway produces normally complex and tarry mixtures), in the photoreaction carried out in an air equilibrated solution (Scheme 1). This oxidation regenerates starting material, and the result is a low efficient and rather selective photosubstitution process. A very similar behavior has been reported for the ground state reactions of nitroaryl halides with isopropanol in basic media. ${ }^{21,22}$

Irradiation of a TCCI substrate, tetrafluoroborate of $N$-methyl- $N$-(2-(2-methoxy-4nitrophenoxy)ethyl)piperidinium 3 under the same conditions in an air equilibrated solution gave rise to the phenol 7 (32\% yield), 4-nitroveratrole 1 (40\% yield) and 2-methoxy-5-nitrophenol 6 (13\% yield). In this case, only $14 \%$ of starting material was recovered (86\% conversion). In this experiment the high conversion, and the almost complete chemoselectivity (since only photosubstitution products are produced) are remarkable. In addition, the regioselectivity observed is different from the one reported in the previous paragraph for the photoreaction of a simple nitrophenyl ether. Hence, para substitution with respect to the nitro group predominates, suggesting the radical anion is now operative in the substitution pathway $\left(\mathrm{S}_{\mathrm{N}} \mathrm{Ar}^{*}\right.$-SET mechanism). ${ }^{10,11}$ This was confirmed by carrying out the photoreaction under an inert atmosphere. In the absence of the TCCI effects, only photoreduction was observed in these conditions; however, irradiation of tetrafluoroborate 3, in an argon atmosphere produced $16 \%$ of 
phenol 7, 58\% of nitroveratrole 1, and 19\% of 2-methoxy-5-nitrophenol $\mathbf{6}$, all of them photosubstitution products with a conversion over 93\% (Scheme 3).<smiles>CCOc1ccc([N+](=O)[O-])cc1OC</smiles>

(2)

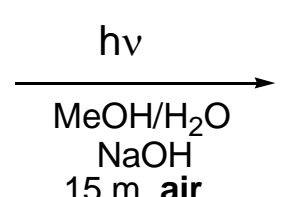

Conversion $=33 \%$<smiles>CCOc1ccc([N+](=O)[O-])cc1O</smiles>

(5)<smiles>COc1ccc([N+](=O)[O-])cc1OC</smiles>

(1)<smiles>COc1ccc([N+](=O)[O-])cc1O</smiles>

(6)<smiles>CCOc1ccc([N+](=O)[O-])cc1OC</smiles>

(2)

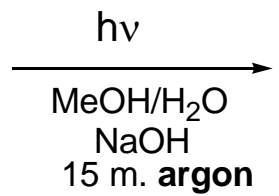

Conversion $=33 \%$

\section{Scheme 2}

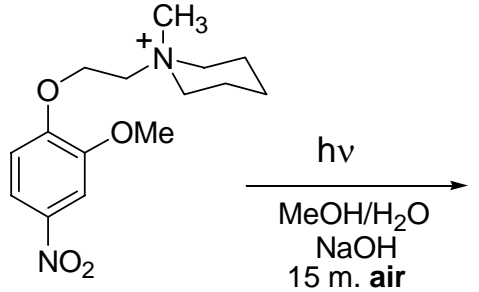

(3)

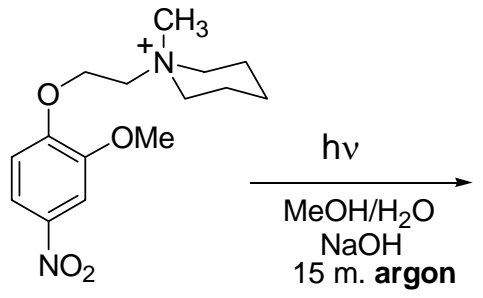

(3)

Conversion $=93 \%$<smiles>CCC[N+](C)(C)CCOc1ccc([N+](=O)[O-])cc1O</smiles>

(7)<smiles>CCC[N+](C)(C)CCOc1ccc([N+](=O)[O-])cc1O</smiles>

(7)<smiles>COc1ccc([N+](=O)[O-])cc1OC</smiles>

(1)<smiles>COc1ccc([N+](=O)[O-])cc1OC</smiles>

(1)<smiles>COc1ccc([N+](=O)[O-])cc1O</smiles>

(6)<smiles>COc1ccc([N+](=O)[O-])cc1O</smiles>

(6)

\section{Scheme 3}

The obvious interpretation in the light of the mechanistic scheme depicted in Scheme 1, is that the TCCI produces two effects, on one hand, the radical anion is less prone to be oxidized, and therefore the general efficiency of the photoprocess in an air atmosphere increases, and on 
the other hand, the radical anion is less basic, and therefore, its protonation (key step in the photoreduction pathway, Scheme 1) is slower, which allows the SET-photosubstitution to occur.

In order to establish the influence of the positive charge on the outcome of the photoreaction, the influence of the average distance of the ammonium group to the aromatic ring in the production of the different photoproducts was studied. Thus, in Scheme 4 the preparative yields for the photoreactions of tetrafluoroborates $\mathbf{3}$ and $\mathbf{4}$ are compared and with the corresponding photoreaction in the absence of positive charge, (4-ethoxy-3-methoxy-nitrobenzene 2). By comparison with similar photoreactions, ${ }^{10,11}$ the meta-phenols 5,7 , and $\mathbf{8}$, must proceed through the $\mathrm{S}_{\mathrm{N}} \mathrm{Ar}$-polar pathway, while 4-nitroveratrole 1 and 2-methoxy-5-nitrophenol $\mathbf{6}$ must be of SET origin (Scheme 1). This is confirmed by the results described in Scheme 4. Thus, on shortening the linker between the ammonium group and the phenyl ring, all the yields of photosubstitution products increase (disappearance of the photoreduction process), but this effect is much more intense for photoproducts $\mathbf{1}$ and $\mathbf{6}$. This result demonstrated the different origin of the meta-phenols (5, 7, and $\mathbf{8}$ ) on one side, and photoproducts $\mathbf{1}$ and $\mathbf{6}$ on the other, and that the pathway that leads to those latest is much more sensitive to the TCCI effects, thus confirming the operativity as intermediate of the aromatic radical anion (zwiterion).

As a conclusion, the ability of TCCI effects to alter the normal photoreactivity of nitrophenyl ethers in front of nucleophiles has been demonstrated. A selective photoreactivity change from SET-photoreduction to photosubstitution (major SET-photosubstitution) can be achieved by introducing a positive charge in a controlled way (opposite to the nitro group) in the structure of a nitrophenyl ether.<smiles>[R]Oc1ccc([N+](=O)[O-])cc1OC</smiles>

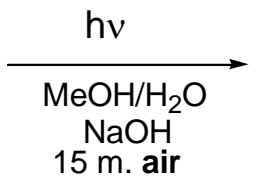

(3)

(4) $\mathrm{R}=\left(\mathrm{CH}_{2}\right)_{5} \mathrm{~N}^{+}\left(\mathrm{CH}_{3}\right) \mathrm{C}_{5} \mathrm{H}_{10}$

(2) $\quad \mathrm{R}=\mathrm{Et}$<smiles>[R]Oc1ccc([N+](=O)[O-])cc1O</smiles>

$32 \%(7)$

$22 \%(8)$

$20 \%(5)$<smiles>COc1ccc([N+](=O)[O-])cc1OC</smiles><smiles>COc1ccc([N+](=O)[O-])cc1O</smiles>

$13 \%$

$3 \%$

traces

\section{Scheme 4}

\section{Experimental Section}

General Procedures. 4-Nitroveratrole (1) was prepared by nitration of veratrole. ${ }^{23}$ Potassium 2methoxy-4-nitrophenoxide was prepared according to the method of Pollecoff and Robinson. ${ }^{24}$ $N$-methyl- $N$-(2-(2-methoxy-4-nitrophenoxy)ethyl)piperidinium tetrafluoroborate (3) and $\mathrm{N}$ methyl- $N$-(5-(2-methoxy-4-nitrophenoxy)pentyl)piperidinium tetrafluoroborate (4) were prepared as previously reported. ${ }^{2}$ 
3-Methoxy-4-ethoxynitrobenzene (2). Potassium 2-methoxy-4-nitrophenoxide dihydrate (0.0193 mol), ethyl bromide $(0.188 \mathrm{~mol})$, and $100 \mathrm{~mL}$ of butanone were introduced in a round.bottomed flask. The mixture was kept under reflux for $24 \mathrm{~h}$. Then, the solvent and the excess ethyl bromide were evaporated. The residue was dissolved in $40 \mathrm{~mL}$ of chloroform, and the organic solution was washed with sodium hydroxide $(1 \mathrm{M})$ and water and dried and the solvent evaporated. The product is recrystallized in methanol (3.0 g, 79\% yield): $\mathrm{mp} 85-8{ }^{\circ} \mathrm{C}$ (Lit. ${ }^{25} 85^{\circ} \mathrm{C}$ ); ${ }^{1} \mathrm{H} \mathrm{NMR}\left(\mathrm{CDCl}_{3}\right) \delta 2.5$ (t, $\left.J=7,3 \mathrm{~Hz}, 3 \mathrm{H}\right), 4.0(\mathrm{~s}, 3 \mathrm{H}), 4.2$ (q, $\left.J=7.3 \mathrm{~Hz}, 2 \mathrm{H}\right), 6.9$ (d, $J=8.5 \mathrm{~Hz}, 1 \mathrm{H}), 7.8$ ( d, $J=2.4 \mathrm{~Hz}, 1 \mathrm{H}$ ), 7.9 ( dd, $J=8.5 \mathrm{~Hz}, J=2.4 \mathrm{~Hz}, 1 \mathrm{H}$ ).

\section{General procedure for the photochemical reactions described in Schemes 2, 3, and 4}

In a $600 \mathrm{~mL}$ Pyrex photochemical reactor, 0,52 mmol of the corresponding photoreagent in 500 $\mathrm{mL} \mathrm{NaOH} \mathrm{(0.1M)} \mathrm{solution} \mathrm{in} \mathrm{MeOH} / \mathrm{H}_{2} \mathrm{O}(1: 1 \mathrm{v} / \mathrm{v})$, were introduced. The solution was irradiated 15 min., at room temperature, with a $400 \mathrm{~W}$ medium-pressure Hg lamp. Then, the reaction mixture was acidified with aqueous fluoroboric acid, and was extracted with chloroform. The aqueous layer was evaporated and the residue digested with methanol. Ammonium tetrafluoroborates (7 or 8) were obtained from this solution, after filtering the insoluble inorganic salts. The organic layer was extracted again with a $\mathrm{NaOH}$ solution (1M), the organic layer dried and the solvent evaporated, obtaining 4-nitroveratrole 1. Finally, the aqueous layer of the last extraction was acidified with $\mathrm{HCl}(1 \mathrm{M})$ and extracted again with chloroform. After drying of the organic layer and evaporation of the solvent, phenol $\mathbf{6}$ was obtained. Characterization of products $\mathbf{1}$ and $\mathbf{6}$ was done by comparison with authentic samples. In the case of products $\mathbf{7}$ and $\mathbf{8}$, complete characterization was not possible, but due to their very similar structure to the corresponding starting material (only a methyl group is missing), the structure was assigned by comparison of their NMR spectra with the one of the corresponding starting material. ${ }^{2}$ This assignment was confirmed by methylation with methyl iodide. The corresponding starting material was obtained in each case.

$\boldsymbol{N}$-Methyl- $\boldsymbol{N}$-(2-(2-hydroxy-4-nitrophenoxy)ethyl)piperidinium tetrafluoroborate (7). ${ }^{1} \mathrm{H}$ NMR (deuterated methanol) $\delta 1.60$ (m, 2H), 1.90 (m, 4H), 3.15 (s, 3H), 3.40 (m, 2H), 3.50 (m, 2H), 3.85 (m, 2H), 4.55 (m, 2H), 7.05 (d, $J=8 \mathrm{~Hz}, 1 \mathrm{H}$ ), 7.50 (dd, $J=8 \mathrm{~Hz}, J=2.4 \mathrm{~Hz}, 1 \mathrm{H}), 7,60$ (d, $J=2.4 \mathrm{~Hz}, 1 \mathrm{H})$.

$\boldsymbol{N}$-Methyl- $\boldsymbol{N}$-(5-(2-hydroxy-4-nitrophenoxy)pentyl)piperidinium tetrafluoroborate (8). ${ }^{1} \mathrm{H}$ NMR (deuterated methanol) $\delta 1.60-2.00(\mathrm{~m}, 12 \mathrm{H}), 3.10(\mathrm{~s}, 3 \mathrm{H}), 3.35-3.45(\mathrm{~m}, 6 \mathrm{H}), 4.20$ (t, $J=6$ Hz, 2H), 7.05 (d, $J=8 \mathrm{~Hz}, 1 \mathrm{H}), 7.50$ (dd, $J=8 \mathrm{~Hz}, J=2.4 \mathrm{~Hz}, 1 \mathrm{H}), 7,60$ (d, $J=2.4 \mathrm{~Hz}, 1 \mathrm{H}$ ).

\section{Acknowledgments}

Financial support of the DGI (MCyT of Spain) through project BQU2000-0336 and the “Generalitat de Catalunya” through project 2001SGR00180 is gratefully acknowledged. 


\section{References}

1. Cayón, E.; Marquet, J.; Lluch, J. M.; Martin, X. J. Am. Chem. Soc. 1991, 113, 8970.

2. Marquet, J.; Cayón, E.; Martín, X.; Casado, F.; Gallardo, I.; Moreno, M.; Lluch, J. M. J. Org. Chem. 1995, 60, 3814.

3. Gonzalez-Blanco, R.; Bourdelande, J. L.; Marquet, J. J. Org. Chem. 1997, 62, 6910.

4. Azzena, U.; Casado, F.; Fois, P.; Gallardo, I; Pisano, L.; Marquet, J.; Melloni, G. J. Chem Soc., Perkin Trans. 2 1996, 2563.

5. Casado, F.; Pisano, L.; Farriol, M.; Gallardo, I.; Marquet, J.; Melloni, G. J. Org. Chem. 2000, 65, 322.

6. Cornelisse, J.; Havinga, E.; Chem Rev. 1975, 75, 353 and references therein.

7. Van Riel, H. C. H. A.; Lodder, G.; Havinga, E. J. Am. Chem. Soc. 1981, 103, 7257.

8. Mutai, K.; Kobayashi, K.; Yokoyama, K. Tetrahedron 1984, 40, 1755.

9. Bunce, N. J.; Cater, S. R.; Scaiano, J. C.; Johnston, L. J. J. Org. Chem 1987, 52, 4214.

10. Cantos, A.; Marquet, J.; Moreno-Mañas, M.; Castelló, A. Tetrahedron 1988, 44, 26607.

11. Van Eijk, A. M. J.; Huizer, A. H.; Varma, C. A. G. O.; Marquet, J. J. Am. Chem. Soc. 1989, 111, 88.

12. Cantos, A.; Marquet, J.; Moreno-Mañas, M.; González-Lafont, A.; Lluch, J. M.; Bertrán, J. J. Org. Chem. 1990, 55, 3303.

13. Trotter, W.; Testa, A. C. J. Am. Chem. Soc. 1968, 90, 7044.

14. Mir, M.; Marquet, J. Massot, O. Tetrahedron 1999, 55, 12603.

15. Petersen, W. C.; Letsinger, R.L. Tetrahedron Lett. 1971, 2197.

16. Varma, C. A. G. O.; Plantenga, F. L.; Huizer, A. H.; Zwart, J. P.; Bergwerf, Ph.; van de Ploeg, J. P. M. J. Photochem. 1984, 24, 133.

17. Van Zeijl, P. H. M.; van Eijk, A. M. J.; Varma, C. A. G. O. J. Photochem. 1985, 29, 415.

18. Wubbels, G. G.; Susens, D. P.; Coughlin, E. B. J. Am. Chem. Soc. 1988, 110, 2538.

19. Hayon, E.; Simic, M. Acc. Chem. Res. 1974, 7, 114.

20. Marquet, J.; Cantos, A.; Moreno-Mañas, M.; Cayón, E.; Gallardo, I. Tetrahedron 1992, 48, 1333.

21. Arca, V.; Paradisi, C.; Scorrano, G. J. Org. Chem. 1990, 55, 3617.

22. Paradisi, C.; Scorano, G. In Nucleophilicity Adv. Chem. Ser. 1987, 215, 339.

23. Vermeulen, M. H. Recl. Trav. Chim. Pays-Bas 1906, 25, 12.

24. Pollecoff, F.; Robinson, R. J. Chem. Soc. 1918, 113, 645.

25. Yoshimura, H. Chem. Pharm. Bull. 1966, 14, 939. 